\title{
Properties of Rice Stem Extracts Obtained by Subcritical Water/Ethanol Treatment
}

\author{
Boonnakhom Tangkhavanich, Yukie Oishi, Takashi Kobayashi and Shuji Adachi \\ Division of Food Science and Biotechnology, Graduate School of Agriculture, Kyoto University, Sakyu-ku, Kyoto 606-8502, Japan
}

Received January 24, 2013; Accepted March 13, 2013

\begin{abstract}
Rice straw stem was treated with subcritical water, ethanol, or a mixture at $170^{\circ} \mathrm{C}$ to $230^{\circ} \mathrm{C}$. The yield, total carbohydrate content, UV-Vis absorption spectra, phenolic content, radical scavenging activity, and HPLC analysis of the extracts were determined. Higher stem extract yield and total carbohydrate content were achieved when the stem was treated using a subcritical ethanol/water mixture with high ethanol content and at the higher temperature. A maximum yield and total carbohydrate content of $0.387 \pm 0.004$ $\mathrm{g} / \mathrm{g}$-stem and $0.219 \pm 0.021 \mathrm{~g} / \mathrm{g}$-stem, respectively, were achieved when the stem was treated with $50 \%$ (v/ v) ethanol at $230^{\circ} \mathrm{C}$. The extract obtained using $75 \%(v / v)$ ethanol at $230^{\circ} \mathrm{C}$ had the highest total phenolic content and radical scavenging activity of $45.2 \pm 1.1 \mathrm{mg}$-gallic acid equiv./g-stem and $0.308 \pm 0.022 \mathrm{mmol}-$ vitamin $\mathrm{C}$ equiv./g-stem, respectively.
\end{abstract}

Keywords: extraction, radical scavenging, rice straw, subcritical fluid

\section{Introduction}

Rice straw is very abundant and is considered an agricultural waste (Dominguez-Escriba and Parcar, 2010; Kadam et al., 2000). Many applications of rice straw have been investigated; however, the amount of rice straw utilized remains very low compared to the worldwide annual production. The three major components of rice straw are cellulose, hemicellulose, and lignin, which are considered to contain promising substances (Lawther et al., 1996). Due to the hydrogen bonds between the glucose molecules of cellulose and the covalent bonds in lignin, rice stem is only slightly soluble in water at ambient temperature (Xiao et al., 2001). At high temperatures $\left(100^{\circ} \mathrm{C}\right.$ to $\left.374^{\circ} \mathrm{C}\right)$, water can maintain its liquid state under pressurized conditions, and is called subcritical water or compressed hot water. The ion product of subcritical water increases to over $1 \times 10^{3}$ fold greater than that of water at room temperature (Marshall and Franck, 1981; Wagner and Pruß, 2002). Due to high concentrations of hydroxium and hydroperoxide ions, subcritical water has the ability to hydrolyze hemicellulose, lignin, and the amorphous part of cellulose. Another feature is its low dielectric constant, which can be adjusted by controlling the temperature. The dielectric constant of water decreases from 80 at ambient temperature to 27 at $250^{\circ} \mathrm{C}$. The dielectric constant of subcritical water

*To whom correspondence should be addressed.

E-mail: adachi@kais.kyoto-u.ac.jp matches that of ethanol or acetone at room temperature. With these features, water under subcritical conditions can liberate phenolic compounds, which are bonded to the carbohydrate backbone (Bobleter, 1994; Kumar et al., 2010).

Chiou et al. (2012) reported that a subcritical water/ethanol mixture could more effectively extract protein, carbohydrate, and phenolic compounds from defatted rice bran than subcritical water or ethanol alone. The addition of ethanol enhances extraction efficiency because constituents with different polarities in the extract are obtained by the ethanol and water (Durling et al., 2007; Richter et al., 1996). Other advantages of ethanol are that it is inexpensive, easy to remove, and has low toxicity. Additionally, in the subcritical state, the surface tension and viscosity of water and ethanol decrease with increasing temperature. The decrease in the surface tension permits the constituents to more easily dissolve in the solvent, while the decrease in viscosity allows the solvent to penetrate into the stem matrix (Kumar et al., 2010; Richter et al., 1996). Based on these reasons, a mixture of water and ethanol was used as an extractant in this study.

The effects of treatment temperature and ethanol content in the extractant on the properties of the rice stem extract were investigated. Rice stem without leaves was selected as the sample subjected to subcritical water/ethanol treatment, because the rice stem has a higher yield, total carbohydrate content, and phenolic content than the rice leaf (Tangkhavanich et al., 2012). The aim of this study is the optimization 
of extraction conditions in terms of yield, carbohydrate content, and the content of phenolic compounds from rice stem.

\section{Materials and Methods}

Materials Rice straw (Oryza sativa) cultivated in the Hyogo Prefecture of Japan was used as the sample. The rice straw sample was kept at $4^{\circ} \mathrm{C}$ in a storage room after drying in the sun. The rice stem was separated from the rice straw and cut into 1-cm long pieces. L-Ascorbic acid (abbreviated VC; purity $>99.5 \%$ ) was purchased from Nacalai Tesque (Kyoto, Japan). Gallic acid was from Sigma-Aldrich Japan (Tokyo, Japan). Folin-Ciocalteu's phenol reagent was from ICN Biochemicals (Aurora, OH, USA). 1,1-Diphenyl-2-picrylhydrazyl (DPPH) and all other chemicals of reagent grade were from Wako Pure Chemical Industries (Osaka, Japan). Distilled water was used in all the experiments.

Subcritical water/ethanol treatment A 117-mL SUS-316 stainless steel vessel $(30 \mathrm{~mm}$ i.d. $\times 165.5 \mathrm{~mm})$ assembled by Taiatsu Techno (Osaka, Japan) was used as the extraction vessel. Five g of rice stem and $55 \mathrm{~mL}$ of water, ethanol, or a mixture of the two were added to the vessel. The vessel was tightly closed and heated to the desired temperature using a mantle heater (200 W; Sogo Laboratory Glass Works, Kyoto, Japan). The temperature inside the vessel during treatments was measured by a thermocouple inserted into a tube installed in the vessel. The desired temperature was maintained for $5 \mathrm{~min}$, exclusive of the heat-up time of $7^{\circ} \mathrm{C} / \mathrm{min}$. The vessel was placed in an ice bath to immediately cool the extract to room temperature after the treatment. To obtain the clarified extracts, the crude extracts were filtered through Advantec filter paper (No. 2; Toyo Roshi, Tokyo, Japan). The stem extracts were stored in a refrigerator at $4^{\circ} \mathrm{C}$ until used for analysis.

Yield of extract After a $15-\mathrm{mL}$ portion of the liquid stem extract was lyophilized using an FDU-1200 freeze-dryer (Tokyo Rikakikai, Tokyo, Japan), the lyophilized extracts were placed in a hot-air oven (DN 400; Yamato Scientific, Tokyo, Japan) at $105^{\circ} \mathrm{C}$ for $3 \mathrm{~h}$ to ensure dryness. The extract yield was calculated by dividing the weight of the dry solid extract by that of the dry rice stem.

Total carbohydrate content The carbohydrate content of the stem extract was measured by the modified phenolsulfuric acid method (Dubois et al., 1956). A 1-mL diluted extract or glucose standard solution was added to a $25 \mu \mathrm{L}$ aliquot of $80 \%(\mathrm{w} / \mathrm{w})$ aqueous phenol solution and $2.5 \mathrm{~mL}$ of sulfuric acid and mixed well. The mixture was kept at room temperature for $10 \mathrm{~min}$ and then placed in a $30^{\circ} \mathrm{C}$ water bath for another $10 \mathrm{~min}$. Absorbance at $490 \mathrm{~nm}$ was measured using a UV-1200 spectrophotometer (Shimadzu, Kyoto, Japan).

Total phenolic content The diluted stem extract (100 $\mu \mathrm{L}$ ) was placed in a test tube and mixed with $400 \mu \mathrm{L}$ of freshly prepared Folin-Ciocalteu's reagent and $1 \mathrm{~mL}$ of 75 $\mathrm{g} / \mathrm{L}$ sodium carbonate (Iqbal et al., 2005; Singleton and Rossi, 1965). The mixture was then filled to $5 \mathrm{~mL}$ with distilled water and kept in the dark at room temperature for $2 \mathrm{~h}$ to complete the reaction. Absorbance at $765 \mathrm{~nm}$ was measured. The total phenolic content was compared with that of gallic acid and expressed as the gallic acid equivalent (mg-gallic acid/g-straw).

Radical-scavenging activity A mixture of $4 \mathrm{~mL}$ of diluted rice stem extract and $1 \mathrm{~mL}$ of $0.5 \mathrm{mmol} / \mathrm{L}$ DPPH in ethanol was placed in a black tube. The solution was mixed well and kept at room temperature for $20 \mathrm{~min}$. Absorbance at $516 \mathrm{~nm}$ was measured to estimate the remaining radical quantity. The radical scavenging activity as a percentage was calculated as follows (Fujinami et al., 2001):

Radical scavenging activity $=(A-B+C) / A \times 100$

where $A$ is the initial absorbance of the control, $B$ is the absorbance of the diluted sample or standard solution, and $C$ is the absorbance of the diluted extract or standard solution without the DPPH solution. The radical scavenging activity of a stem extract was defined as the amount of extract necessary to reduce the initial DPPH concentration by $50 \%$. L-Ascorbic acid was used as the standard. The results were expressed as mmol-VC equiv./g-straw.

HPLC analysis of extract The extracts obtained from the first repetition were analyzed using an LC-10AD HPLC (Shimadzu) equipped with a Hydrosphere C18 column (3 $\mathrm{mm}$ i.d. $\times 150 \mathrm{~mm}$; YMC, Kyoto, Japan), a guard column (10 mm i.d. $\times 30 \mathrm{~mm}$; YMC), and an SPD-10A UV detector (Shimadzu). The 100-fold diluted extract $(20 \mu \mathrm{L})$ was applied to the column and eluted at $0.3 \mathrm{~mL} / \mathrm{min}$ in the gradient mode. Distilled water was employed as the eluent from 0 to $10 \mathrm{~min}$. From 10 to $60 \mathrm{~min}$, the methanol concentration in the eluent linearly increased from $0 \%$ to $100 \%$ and was maintained at $100 \%$ from 60 to $80 \mathrm{~min}$. The elution profile was monitored by absorbance at $280 \mathrm{~nm}$.

UV-Vis absorption spectra The stem extracts of the first repetition were diluted with distilled water to attain an absorbance of less than unity for both UV and visible measurements. The absorbance of the extracts was then measured from 200 to $500 \mathrm{~nm}$.

Statistical analysis All the experiments were conducted in triplicate. The obtained results were analyzed for means, standard deviations, and correlations using Microsoft ${ }^{\circledR}$ Excel 2010.

\section{Results and Discussion}

Effects of treatment temperature and ethanol concentra- 
tion on the properties of extracts Figure $1 \mathrm{a}$ and $1 \mathrm{~b}$ shows the yields and carbohydrate contents of the extracts obtained using extractants of different ethanol concentrations. The yield and carbohydrate content of the extract demonstrated a similar tendency. One of the reasons for this similarity is that the major source of carbohydrates in the extracts is hemicellulose, and that the rice straw consists of approximately $24 \%$ hemicellulose (Kadam et al., 2000). At $170^{\circ} \mathrm{C}$, the yield and carbohydrate content were constant until 50\% (v/v) ethanol, decreasing slightly thereafter. The yield and carbohydrate content linearly decreased with the increasing ethanol concentration at $200^{\circ} \mathrm{C}$. According to our previous study, the majority of decomposition of the rice stem cell wall occurred at the treatment temperature (Tangkhavanich et al., 2012). This decrease suggests that the extraction efficiency of subcritical water may be disrupted by the increasing ethanol concentration. When treated at $230^{\circ} \mathrm{C}$, the yield and carbohydrate content increased until $50 \%(\mathrm{v} / \mathrm{v})$ ethanol and then drastically decreased. Under subcritical water conditions, it was reported that the degradation reactions occurred more rapidly at the higher temperature (Khajavi et al., 2005; Wiboonsirikul et al., 2007). The subcritical 50\% (v/v) ethanol at $230^{\circ} \mathrm{C}$ might be the point at which the extraction efficiency and carbohydrate degradation are balanced. This indicates that the increase in yield and total carbohydrate content would be due to the presence of water, while ethanol reduces degradation of the extracted carbohydrates. When the solvent contained more ethanol, a higher treatment temperature was needed in order to achieve the maximum yield. This may be related to the presence of water in the system, in which the higher ion product of water would be required to disrupt the rice stem cell wall structure through hydrolysis. The decrease in the water fraction would result in a decreased ion product. Thus, the higher treatment temperature was necessary to increase the ionization constant of water. This could also be the reason for the lower yields and carbohydrate contents of the extracts obtained using subcritical ethanol than those of the extracts obtained using subcritical water and the ethanol/ water mixtures at any treatment temperature.

At the lower treatment temperature of $170^{\circ} \mathrm{C}$, the ethanol concentration did not significantly affect the phenolic content of the extracts (Fig. 1c). This may be because cell wall disruption did not significantly occur at this temperature. However, at the higher temperatures, the phenolic content increased with increasing ethanol concentration up to $75 \%$. This increase might be because the main source of the phenolic compounds in vascular plants is lignin, which crosslinks to cellulose and hemicellulose to form the cell wall structure (Sarkanen and Ludwig, 1971). At elevated temperatures, disruption of the cell wall occurred and subsequently

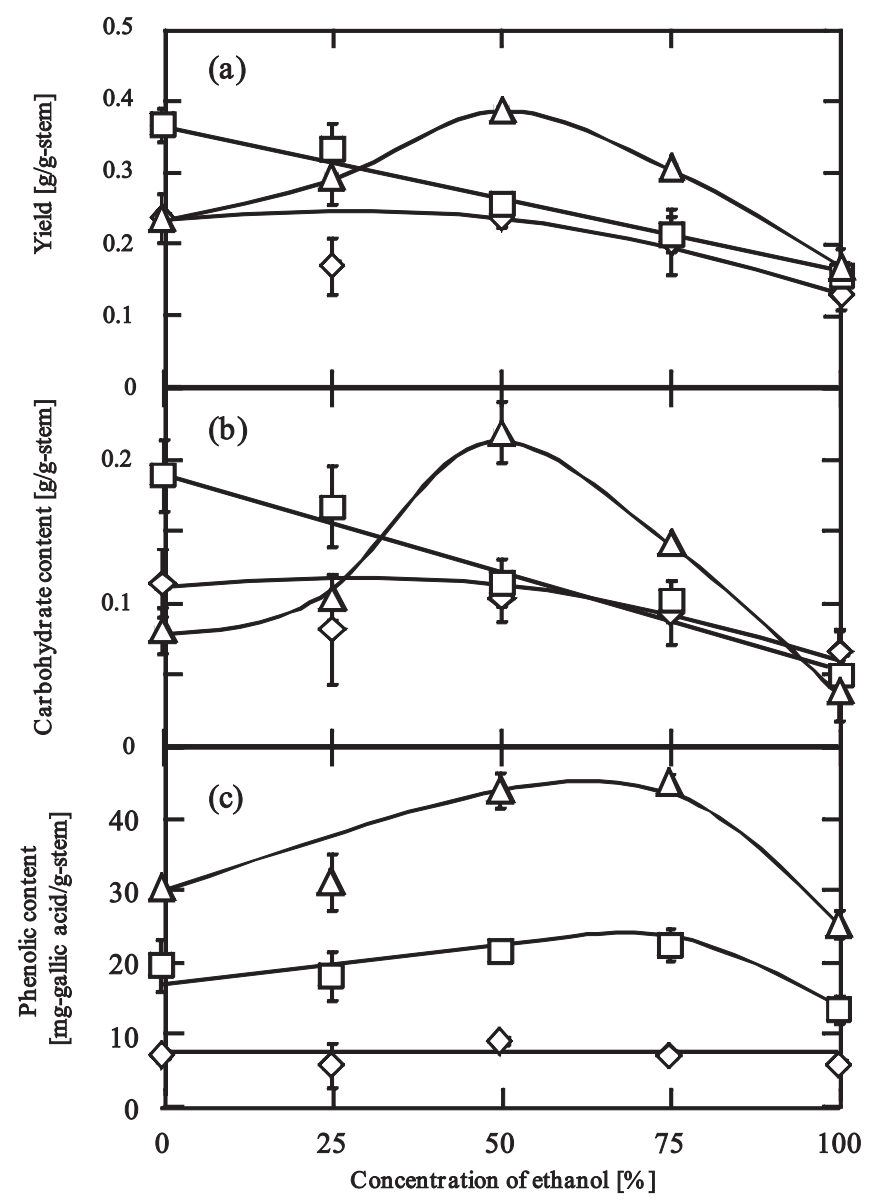

Fig. 1. Yield, total carbohydrate content, and phenolic content of extracts obtained using different subcritical fluids at $170^{\circ} \mathrm{C}-230^{\circ} \mathrm{C}$. (a) Yield, (b) carbohydrate content, and (c) phenolic content at $(\diamond)$ $170^{\circ} \mathrm{C},(\square) 200^{\circ} \mathrm{C}$, and $(\triangle) 230^{\circ} \mathrm{C}$.

released the phenolic substances from the cell wall into the extract (Wiboonsirikul et al., 2007). The total phenolic content of the extract treated with a subcritical ethanol/water mixture was higher than that with subcritical water or ethanol alone. The highest total phenolic content was achieved with rice stem treated with the subcritical $75 \%$ (v/v) ethanol/ water mixture at $230^{\circ} \mathrm{C}$. The polarity of a solvent plays an important role in the extraction process. Ethanol is less polar than water (Rohrschneider, 1973; Snyder, 1974), and phenolic compounds more readily dissolve in a less polar solvent (Lapornik et al., 2005). Additionally, decomposition of the cellular structure also occurs during subcritical water treatment (Savage et al., 1999; Wiboonsirikul et al., 2007), and this would permit an extractant to easily access the inner phenolic compounds. Solubility of phenolic compounds is higher in a mixed subcritical solvent than in subcritical water; therefore, the use of a mixture was advantageous for improving extraction efficiency.

The plots of total carbohydrate content and yield gave three straight lines (Fig. 2); one for the extracts obtained at $170^{\circ} \mathrm{C}\left(R^{2}=0.96\right)$, and the others for those obtained at $200^{\circ} \mathrm{C}$ 


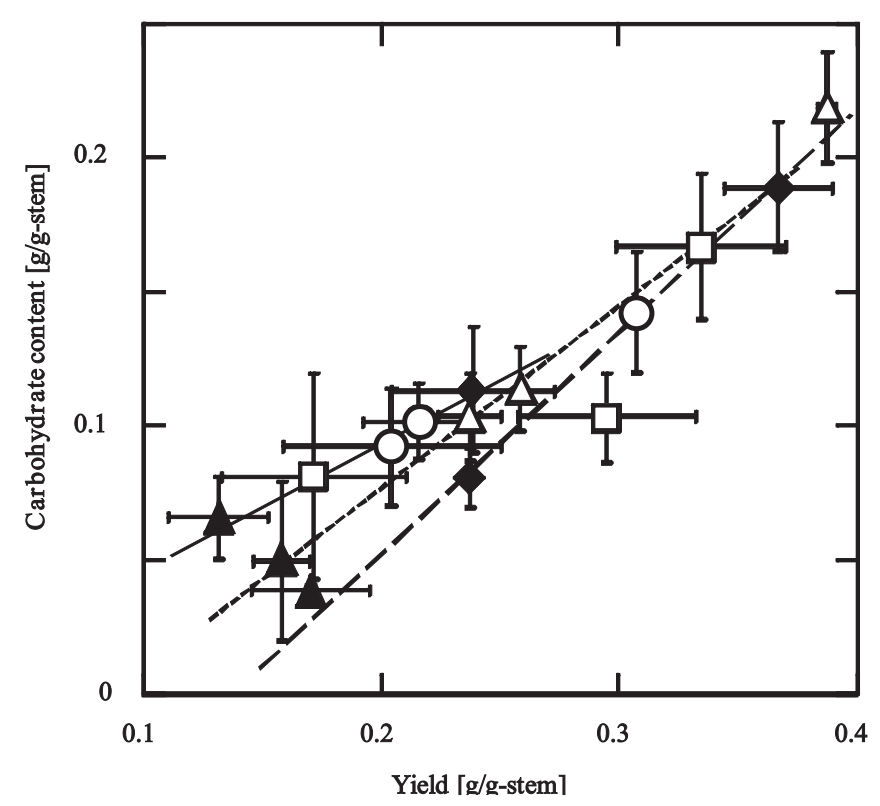

Fig. 2. Relationship between yield and carbohydrate content of rice stem extracts obtained at (-) $170^{\circ} \mathrm{C},(----) 200^{\circ} \mathrm{C}$, and (---) $230^{\circ} \mathrm{C}$ using subcritical $(\diamond)$ water, $(\square) 25 \%(\mathrm{v} / \mathrm{v})$ ethanol/water, $(\triangle)$ 50\% (v/v) ethanol/water, $(\bigcirc) 75 \%(\mathrm{v} / \mathrm{v})$ ethanol/water, and $(\boldsymbol{\Delta})$ ethanol.

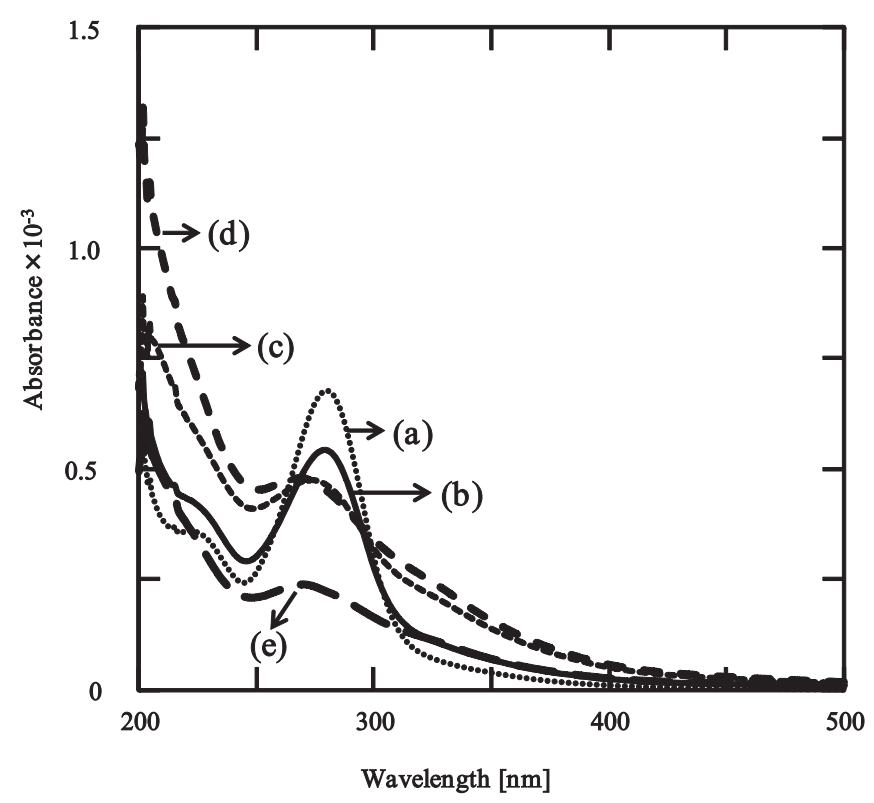

Fig. 3. UV-Vis spectra of rice stem extracts obtained at $230{ }^{\circ} \mathrm{C}$ using subcritical (a) water, (b) 25\% (v/v) ethanol/water, (c) $50 \%(\mathrm{v} / \mathrm{v})$ ethanol/water, (d) 75\% (v/v) ethanol/water, and (e) ethanol.

and $230^{\circ} \mathrm{C}\left(R^{2}=0.98\right.$ and 0.95 , respectively). The slope of those lines indicates the degradation rate of carbohydrates. With increasing treatment temperature, the lines became steeper, suggesting that the degradation of carbohydrate compounds occurred more rapidly.

UV-Vis absorption spectra The UV-Vis spectra of the extracts showed that the extracts obtained using different concentrations of ethanol gave different spectra (Fig. 3), in-

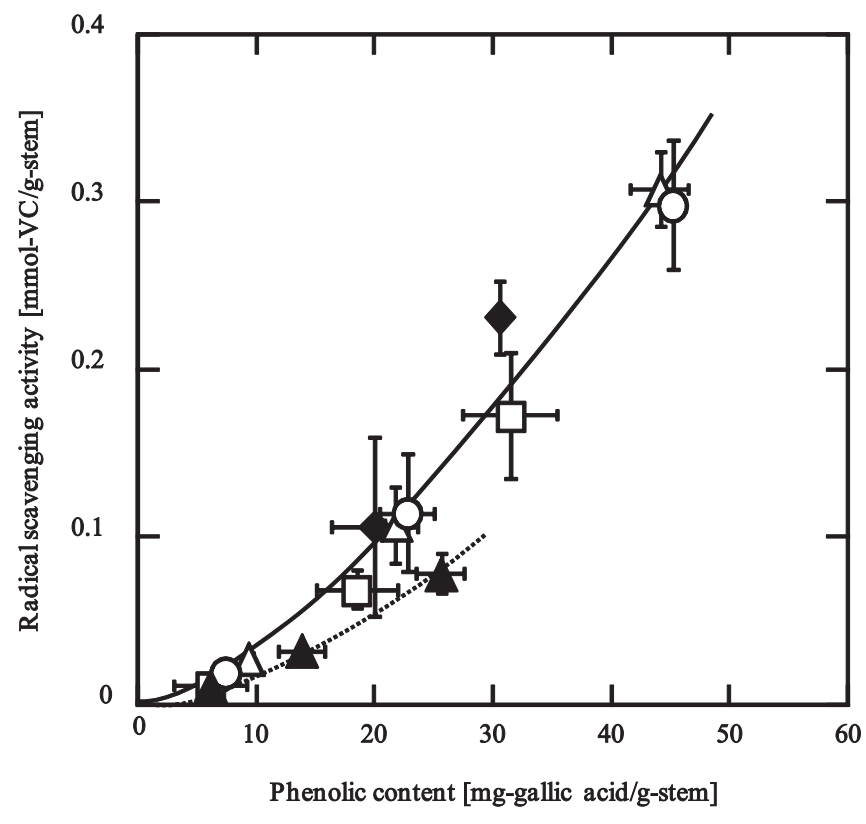

Fig. 4. Relationship between radical scavenging activity and phenolic content of rice stem extracts. The symbols are the same as those in Fig. 2.

dicating the different chemical compositions of the extracts. The UV-Vis spectra of the extracts obtained using subcritical water and a subcritical $25 \%(\mathrm{v} / \mathrm{v})$ ethanol/water mixture showed absorption maxima at about $280 \mathrm{~nm}$ and a small shoulder at about $220 \mathrm{~nm}$. The spectra of the extracts obtained using the subcritical $50 \%$ and $75 \%(\mathrm{v} / \mathrm{v})$ ethanol/water mixtures and subcritical ethanol showed almost the same tendency, i.e., a plateau around $240-260 \mathrm{~nm}$. Absorbances at 200 to $500 \mathrm{~nm}$ of the extracts obtained using the subcritical $50 \%$ and $75 \%(\mathrm{v} / \mathrm{v})$ ethanol/water mixtures were higher than that obtained using subcritical ethanol. The absorbance at $280 \mathrm{~nm}$ suggests the presence of phenolic compounds, which may be derived from lignin (Morrison, 1971; Sun et al., 2010). The lower absorbance around $250 \mathrm{~nm}$ indicates non-lignin materials, such as the decomposition products of carbohydrates and other extractives (Xiao et al., 2001).

Effects of treatment temperature and ethanol concentration on the radical scavenging activities of extracts Many reports have related the radical scavenging activity of plant extracts to their phenolic components (Garrote et al., 2004; Liyana-Pathirana and Shahidi, 2006; Tangkhavanich et al., 2012; Wiboonsirikul et al., 2007). In this study, the radical scavenging activity of the extracts also showed a high correlation $\left(R^{2}=0.97\right)$ to their total phenolic content (Fig. 4). Similar to the total phenolic content, the radical scavenging activity of the extract also increased with increasing treatment temperature; the highest radical scavenging activity of $0.3 \mathrm{mmol}-\mathrm{VC}$ equiv./g-stem was obtained when the rice stem was treated with a subcritical $75 \%(\mathrm{v} / \mathrm{v})$ water/ethanol mixture at $230^{\circ} \mathrm{C}$. The plots of the radical scavenging activi- 


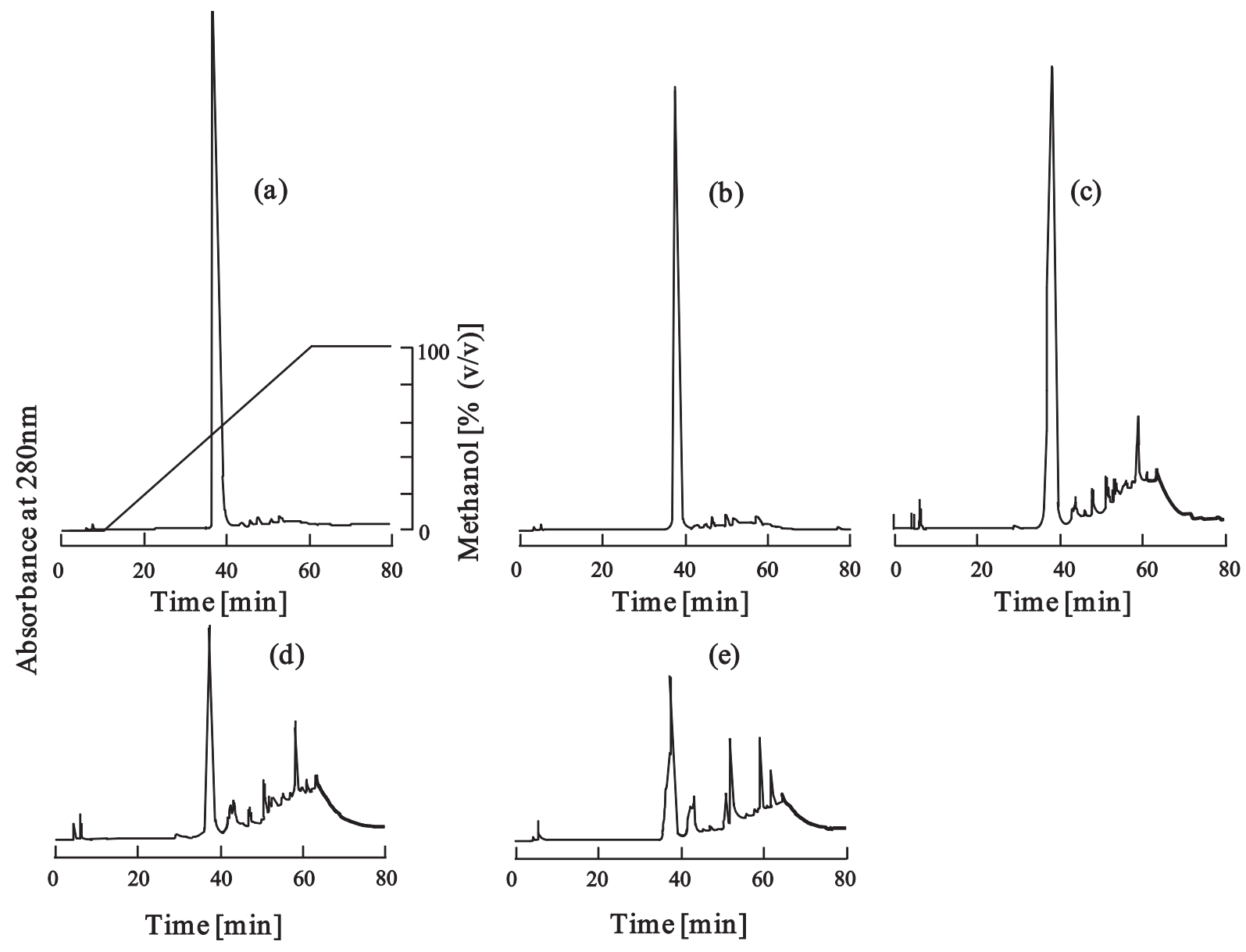

Fig. 5. HPLC chromatograms of rice stem extracts obtained using different subcritical fluids at $230^{\circ} \mathrm{C}$. Labels are the same as those in Fig. 3 .

ties versus the phenolic content gave two curves; one for the extract obtained using the subcritical water and ethanol/water mixtures, and the other for the extracts obtained using subcritical ethanol. These relationships suggest that the phenolic compounds are one of the sources for the radical scavenging activity in the rice stem extract. The radical scavenging activity of the extracts obtained using subcritical ethanol was comparatively lower than that of the extracts obtained using subcritical water and ethanol/water mixtures.

HPLC analysis of the extracts The extracts obtained using different subcritical fluids at $230^{\circ} \mathrm{C}$ were analyzed by HPLC at $280 \mathrm{~nm}$ (Fig. 5). A major peak at around $38 \mathrm{~min}$ was seen in all the extracts. These major peaks decreased with increasing ethanol concentration in the solvent. Meanwhile, the area of the minor peak that appeared around $40-$ 70 min increased with increasing ethanol concentration up to $75 \%$, suggesting that more moderate or less polar phenolic compounds were obtained using the solvent with higher ethanol content. During the extraction, substances are dissolved in the solvent possessing a similar polarity. The addition of ethanol and the increase in temperature decreases the polarity of the solvent (Akerlof, 1932), hence resulting in less polar phenolic compounds being dissolved into the system.
The minor peaks that appeared around $40-70 \mathrm{~min}$ in the subcritical ethanol extract differed from those of the extracts obtained using the subcritical $50 \%$ and $75 \%(\mathrm{v} / \mathrm{v})$ water/ ethanol mixtures. This indicates another reason for the lower radical scavenging activity of the subcritical ethanol extracts.

\section{Conclusions}

Treatment temperature and ethanol concentration affected the properties of the rice stem extract. The yield and total carbohydrate content increased with increasing treatment temperature and ethanol concentration up to $75 \%(\mathrm{v} / \mathrm{v})$. The higher treatment temperature also provided the extracts with a higher total phenolic content and radical scavenging activity. The ethanol concentration had only a slight effect on the quantity of the extracted phenolic compounds, but did affect the type of phenolic compounds dissolved in the subcritical fluids.

Acknowledgments This study was partly financed by the Iijima Foundation.

\section{References}

Akerlof, G. (1932). Dielectric constants of some organic solvent- 
water mixtures at various temperatures. J. Am. Chem. Soc., 54, 4125-4139.

Bobleter, O. (1994). Hydrothermal degradation of polymers derived from plant. Prog. Polym. Sci., 19, 797-841.

Chiou, T.Y., Neoh, T.L., Kobayashi, T. and Adachi, S. (2012). Properties of extract obtained from defatted rice bran by extraction with aqueous ethanol under subcritical conditions. Food Sci. Technol. Res., 18, 37-45.

Dominguez-Escriba, L. and Porcar, M. (2010). Rice straw management: the big waste. Biofuels Bioprod. Biorefin., 4, 154-159.

Dubois, M., Gilles, K.A., Hamilton, J.K., Rebers, P.A. and Smith, F. (1956). Colorimetric method for determination of sugars and related substances. Anal. Chem., 28, 350-356.

Durling, N.E., Catchpole, O.J., Grey, J.B., Webby, R.F., Mitchel, K.A., Foo, L.Y. and Perry, N.B. (2007). Extraction of phenolics and essential oil from dried sage (Salvia officinalis) using ethanol-water mixtures. Food Chem., 101, 1417-1424.

Fujinami, Y., Tai, A. and Yamamoto, I. (2001). Radical scavenging activity against 1,1-diphenyl-2-picrylhydrazyl of ascorbic acid 2-glucoside (AA-2G) and 6-acyl-AA-2G. Chem. Pharm. Bull., 49, 642-644.

Garrote, G., Cruz, J.M., Moure, A., Dominguez, H. and Parajo, J.C. (2004). Antioxidant activity of by-products from the hydrolytic processing of selected lignocellulosic materials. Trends Food Sci. Technol., 15, 191-200.

Iqbal, S., Bhanger, M.I. and Anwar, F. (2005). Antioxidant properties and components of some commercially available varieties of rice in Pakistan. Food Chem., 93, 265-272.

Kadam, L.K., Forrest, H. and Jacobson, W.A. (2000). Rice straw as a lignocellulosic resource: collection, processing, transportation, and environmental aspects. Biomass Bioenerg., 18, 369-389.

Khajavi, S.H., Kimura, Y., Oomori, T., Matsuno, R. and Adachi, S. (2005). Degradation kinetics of monosaccharides in subcritical water. J. Food Eng., 68, 309-313.

Kumar, S., Gupta, R., Lee, Y.Y. and Gupta, R.B. (2010). Cellulose pretreatment in subcritical water: Effect of temperature on molecular structure and enzymatic reactivity. Bioresour. Technol., 101, 1337-1347.

Lapornik, B., Prošek, M. and Wondra, A.G. (2005). Comparison of extracts prepared from plant by-products using different solvents and extraction time. J. Food Eng., 71, 214-222.

Lawther, J.M., Sun, R.C. and Banks, W.B. (1996). Rapid isolation and structural characterization of alkali-soluble lignins during alkaline treatment and atmospheric refining of wheat straw. Ind. Crops Prod., 5, 97-105.
Liyana-Pathirana, C.M. and Shahidi, F. (2006). Antioxidant properties of commercial soft and hard winter wheats (Triticum aestivum L.) and their milling fractions. J. Sci. Food Agric., 86, 477485.

Marshall, W.L. and Franck, E.U. (1981) Ion product of water substance, $0-1000^{\circ} \mathrm{C}, 1-10,000$ Bars; New international formulation and its background. J. Phys. Chem. Ref. Data, 10, 295-304.

Morrison, I.M. (1971). A semi-micro method for the determination of lignin and its use in predicting the digestibility of forage crops. J. Sci. Food Agric., 23, 455-463.

Richter, B.E., Jones, B.A., Ezzell, J.L., Porter, N.L., Avdolovic, N. and Phol, C. (1996). Accelerated solvent extraction: a technique for sample preparation. Anal. Chem., 68, 1033-1039.

Rohrschneider, L. (1973). Solvent characterization by gas-liquid partition coefficients of selected solutes. Anal. Chem., 45, 12411247.

Sarkanen, K.V. and Ludwig, C.H. (1971). "Lignins: Occurrence, Formation, Structure and Reactions.” Wiley-Interscience, New York.

Savage, P.E., Henrikson, J.T. and Benjamin, K.M. (1999). Organic chemical reactions in supercritical water. Chem. Rev, 99, 603621.

Singleton, V.L. and Rossi, J.A. (1965). Colorimetry of total phenolics with phosphomolybdic-phophotungestic acid reagent. Am. J. Enol. Vitic., 16, 144-158.

Snyder, L.R. (1974). Classification of the solvent properties of common liquids. J. Chromatogr., 92, 223-230.

Sun, R.C., Tomkinson, J., Sun, X.F. and Wang, N.J. (2010). Fractional isolation and physico-chemical characterization of alkalisoluble lignins from fast-growing poplar wood. Polymer, 41, 8409-8417.

Tangkhavanich, B., Kobayashi, T. and Adachi, S. (2012). Properties of rice straw extract after subcritical water treatment. Biosci. Biotechnol. Biochem., 76, 1146-1149.

Wagner, W. and Pruß, A. (2002). The IAPWS formation 1995 for the thermodynamic properties of ordinary water substance for general and scientific use. J. Phys. Chem. Ref. Data, 31, 387-535.

Wiboonsirikul, J., Kimura, Y., Kadota, M., Morita, H., Tsuno, T. and Adachi, S. (2007). Properties of extracts from defatted rice bran by its subcritical water treatment. J. Agric. Food Chem., 55, 8759-8765.

Xiao, B., Sun, X.F. and Sun, R.C. (2001). Chemical, structural, and thermal characterizations of alkali-soluble lignins and hemicelluloses, and cellulose from maize stems, rye straw, and rice straw. Polym. Degrad. Stabil., 74, 307-319. 